\title{
Educação em Química e Ensino de Química - Perspectivas curriculares
}

\author{
ISABEL P. MARTINS ${ }^{1}$, MARIA OTILDE SIMÕES ${ }^{2}$, TERESA SOBRINHO SIMÕES ${ }^{3}$, \\ JOSÉ MANUEL LOPES ${ }^{4}$, JOSÉ ALBERTO COSTA ${ }^{1}$, PAULO RIBEIRO-CLARO1
}

O presente trabalho, a ser publicado em duas partes, pretende apresentar e discutir perspectivas que têm vindo a ser assumidas para o ensino das Ciências, em geral, e fazer a sua transposição para o caso da Química, em particular. Os argumentos desenvolvidos dizem respeito à concepção de currículos e programas, seus fundamentos e princípios orientadores. Por razões de clarificação das posições defendidas, procura-se fazer o seu enquadramento em concepções mais abrangentes da educação científica como um valor e ter por referência estudos de investigação em educação em ciências/química. Advoga-se a literacia científica como meta para a concepção e organização do ensino da química o que implica, obrigatoriamente, a ruptura com desenhos curriculares tradicionais.

O diagrama que se segue, pretende organizar as ideias fundamentais subjacentes ao desenvolvimento aqui apresentado:

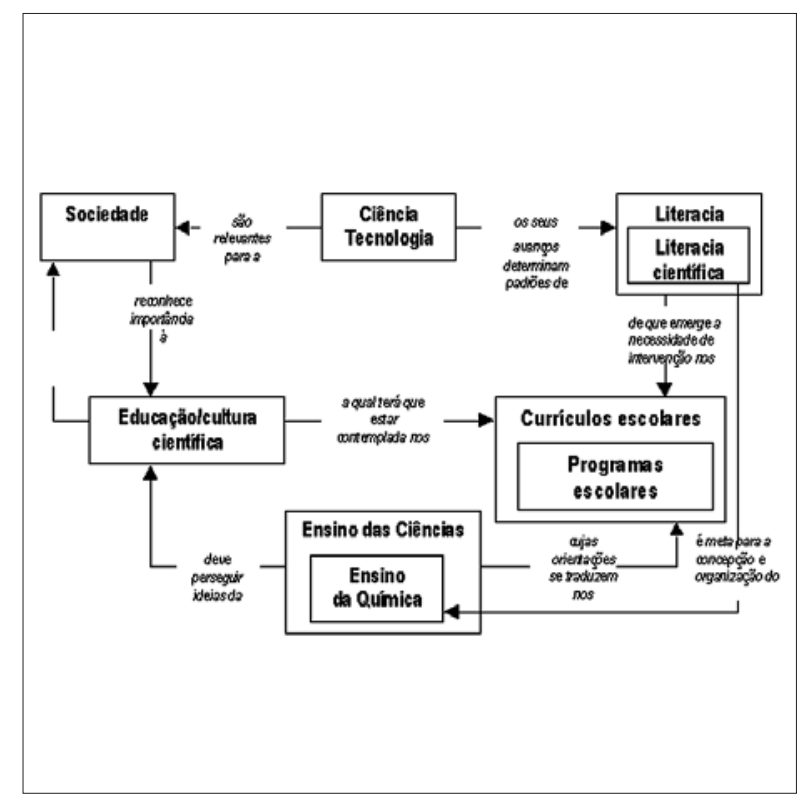

\section{Ciência e Educação em Ciência}

O século XX foi absolutamente marcante em termos de crescimento científico e tecnológico e apesar das críticas de alguns sectores sobre se tal crescimento pode ser tomado como sinónimo de desenvolvimento, é inequívoco que isso trouxe a todos os seres humanos que dele podem usufruir mais bem-estar e melhor qualidade de vida. No entanto, o aumento dos artefactos tecnológicos disponíveis não gera, por si só, conhecimento nos cidadãos e vários estudos conduzidos nas últimas duas décadas têm evidenciado que o público em geral não consegue acompanhar, ainda que de forma rudimentar, as questões científicas manifestando compreensão inade- quada ou desconhecimento total (Eurobarometer, 2001).

Ora, esta situação de crescimento/desenvolvimento é também possível graças ao crescimento explosivo dos níveis de educação das populações. A sociedade mudou, entretanto, profundamente. Nos últimos quarenta anos a população mundial duplicou, e as formas de trabaIhar e de comunicar, os hábitos de consumo e as mentalidades alteraram-se radicalmente, ao ponto de se afirmar que não está em causa, sequer, valorá-las como melhores ou piores, pois os paradigmas em que assentam são diferentes.

As últimas décadas foram particularmente ricas no aumento da consciência social sobre a importância das compe- tências de literacia dos indivíduos, a nível pessoal e sócio-económico das nações, o que se repercutiu na preocupação em precisar o(s) significado(s) do termo e em definir padrões de literacia com aceitação internacional. Este facto veio contribuir para tornar mais visíveis as insuficiências na literacia dos cidadãos e, por isso, a necessidade de encontrar vias para as superar (Wearmouth et al, 2003), o que veio a gerar grandes movimentos de apoio à promoção da literacia dos cidadãos, culminando com a criação da Década da Literacia das Nações Unidas, 2003-2012. Dos debates em torno desta questão, surgidos em diversos pontos do Mundo, emergiu praticamente sempre a necessidade de intervenções nos currículos 
escolares. No entanto, tem sido também claro que a promoção da literacia de todas as pessoas não pode nem deve ficar confinada à escola, embora esta desempenhe um papel fundamental na motivação para a aprendizagem permanente, em particular através da educação não formal, a qual deve continuar ao longo de toda a vida. A literacia assume então um papel instrumental no desenvolvimento das sociedades, ideia traduzida de forma exemplar na expressão "Literacy as Freedom" (Sen, 2003), com o significado de que "não há nada mais fundamental na educação do que a literacia".

Ora, é neste enquadramento de relevância primeira para a literacia (no sentido amplo), que se destaca a importância da Ciência e da Tecnologia nas sociedades contemporâneas como um assunto não controverso hoje em dia, embora não seja isento de polémica o modo como se deve perspectivar a educação formal e não formal em Ciência e Tecnologia. Proliferam propostas sobre formas de organização curricular, a extensão da escolarização em ciências, os objectivos da educação em Ciência e Tecnologia, o tipo de actividades a desenvolver, os recursos a utilizar, a avaliação de competências dos alunos e também do público em geral. Apesar disso, é praticamente aceite que a Escola desempenha um papel fundamental no desenvolvimento do gosto pela aprendizagem das ciências, quer se opte ou não pelo prosseguimento de estudos em Ciências e Tecnologia.

Apesar de toda esta constatação, assiste-se ao desinteresse dos jovens pelas áreas de Ciências e Tecnologia, o que os leva a fazerem opções por outros campos de estudo. Várias associações profissionais têm vindo a alertar para a regressão na procura pelos jovens de cursos de engenharia admitindo que se tal tendência não for corrigida poder-seá recear pelo futuro de algumas actividades industriais e técnicas (Kinstrey, 2004, alerta para carências de quadros na área de Química e Engenharia). Também o começo deste século tem sido particularmente crítico para a investigação científica em muitos países europeus. Por um lado, a União Europeia afirma um elevado interesse em reforçar o seu potencial científico e tecnológico, de modo a tornar-se na maior economia do mundo com base em conhecimento, definindo metas notáveis para o ano 2010, mas, por outro lado e paradoxalmente, assiste-se à estagnação e até a um retrocesso no investimento financeiro e em capital humano necessários para tal. Os movimentos de protesto registados nas comunidades científicas de muitos países europeus estão a ser absolutamente incomparáveis com quaisquer outros no passado.

A discussão sobre o ensino das ciências nos níveis básico e secundário é hoje um tema recorrente nas sociedades dada a importância que se reconhece ao conhecimento científico e a opinião, muito difundida, que as aprendizagens escolares em ciências se revelam como muito deficientes nos testes de literacia científica e, quando é caso disso, remetem os respectivos países para posições pouco confortáveis nas comparações internacionais (estudos de avaliação TIMSS e PISA 2000). No entanto, apesar das críticas que vários sectores da sociedade, praticamente em todos os países que não apresentam posições de topo, têm desenvolvido, são reduzidas as discussões sobre que conteúdos devem ser contemplados nos programas escolares.

Antes disso, e do nosso ponto de vista, há que clarificar os princípios em que deve assentar a organização de currículos e programas de modo a terem em conta o valor da educação em ciência a nível pessoal, social e profissional capaz de salientar a importância do conhecimento científico no desenvolvimento de uma cultura de paz geradora de sociedades mais equilibradas e mais justas.

\section{Educação científica e ensino de química}

Assume-se aqui a posição de diversos autores dispersos por vários pontos do mundo e de organizações como a UNESCO (Conferência Mundial sobre a Ciência, Budapeste, UNESCO, ICSU, 1999), segundo os quais a orientação do ensino das ciências deverá reger-se por princípios que promovam a literacia científica de todos os alunos, pese embora a dificuldade de acordo sobre um conceito único de literacia científica.

[No presente trabalho assume-se como significado de literacia científica, aquele que foi assente no quadro conceptual de referência da OCDE/PISA, isto é, a capacidade de usar conhecimento científico para identificar questões, para estabelecer conclusões a partir de provas, com a intenção de compreender e ajudar a tomar decisões sobre o mundo natural e sobre as modificações nele operadas fruto da actividade humana (OECD, 2000, pp.10; OECD, 2003)].

A discussão que a seguir se desenvolve assume o conhecimento químico como uma parte indelével do conhecimento científico actual, o qual deverá, numa perspectiva de literacia científica para todos, ser parte integrante da educação em ciências, no contexto formal. Assumimos, por isso, que a imagem escolar da Química hoje deverá estar em sintonia com avanços do conhecimento químico (o que não significa entrar precocemente em assuntos complexos).

As ciências químicas mudaram substancialmente nos últimos tempos. Das divisões clássicas como química analítica, química inorgânica, química orgânica, química física, química teórica ou bioquímica evoluiu-se para domínios mais específicos como, por exemplo, nanotecnologia, ciência dos materiais, química computacional. Também a ligação entre química e engenharia química é tida como cada vez mais aprofundada dada a procura de soluções para problemas novos e/ou a capacidade de criar novos produtos os quais passam a constituir-se como necessidades reais da sociedade. É, pois, importante que os alunos se apercebam que os químicos procuram compreender qual é a relação entre a estrutura e as propriedades físicas, químicas e biológicas das substâncias, sejam elas naturais ou sintéticas, com vista a poderem inventar novas substâncias para fins específicos, para o que será também necessário desenvolver processos de síntese laboratorial e de produção industrial, e ainda possam sintetizar substâncias para comprovar/testar teorias. 
Apesar da importância inegável do conhecimento químico para o avanço das sociedades tal constatação não resolve, por si só, a falta de interesse dos jovens pelo estudo da Química, mais acentuado à medida que avançam para níveis de escolaridade superiores (Walberg, Paik, 1997). Para esta situação contribuem vários factores, dos quais se salientam três: (1) a imagem social negativa da Química; (2) o tipo de currículos e programas, de estratégias de ensino e de recursos didácticos; (3) a formação de professores de Química, suas concepções e convicções.

No presente trabalho, abordaremos alguns aspectos referentes ao segundo factor, conscientes, porém, das interdependências com os restantes, bem como dos avanços da investigação em educação em química, uma área do conhecimento que cresceu de forma muito acentuada nas últimas duas décadas, a apreciar o número de publicações dedicadas, de congressos e encontros específicos, de artigos e livros publicados. No entanto, o crescimento da investigação em educação em ciências não está igualmente distribuído pelas várias áreas de ciências, nem pelos níveis de escolaridade. Tendo em conta a dispersão por níveis de escolaridade, podemos afirmar que a preferência na investigação em educação em química vai para o ensino secundário (13-18 anos). Pela natureza dos estudos desenvolvidos, somos compelidos a concluir que não se está a compreender devidamente qual a apetência dos jovens alunos pela aprendizagem da Química, antes mesmo da tomada de decisão por esta área de estudo, nem as implicações de programas e estratégias de ensino de Química, alguns deles bastante promissores. São ainda poucos os estudos que permitem aferir o seu impacte nas aprendizagens dos alunos.

\section{Orientações para o ensino das Ciências}

O ensino das Ciências em contexto escolar, nos últimos séculos, foi fortemente influenciado por um pensamento social sobre o papel do conhecimento. De uma concepção mais útil para a educação das classes trabalhadoras (a "ciên- cia das coisas comuns") passou-se para uma concepção dirigida às elites sociais (a "ciência laboratorial pura"). Esta mudança acompanhou também a evolução do próprio conhecimento científico a nível epistemológico e foi imposta de cima para baixo, isto é, do ensino universitário para o ensino secundário.

No entanto, apesar das evidências da importância da Ciência e Tecnologia para a sociedade, não é irrelevante ponderar que finalidades, que objectivos, que conteúdos e que formas de ensino de Ciências e de Tecnologias são as mais adequadas para a formação dos cidadãos, aspectos sobre os quais existem perspectivas diversas: propedêutica, democrática, funcional, sedutora, útil, pessoal e cultural (Acevedo et al., 2003; Acevedo, 2004).

Apesar das diferenças de forma, em geral, todas as propostas enunciadas por diversos autores se baseiam na democracia como um valor e, por isso, como um objectivo do desenvolvimento humano, e na Ciência como um domínio que persegue ideais de bem para a Humanidade. Segundo Cachapuz e colaboradores (2002) a educação em Ciências deve perseguir ideais de cultura científica dos alunos, por oposição a uma lógica de mera instrução científica, que promovam o desenvolvimento pessoal dos alunos e Ihes permitam alcançar uma participação social esclarecida.

Sendo certo que não é legítimo atribuir à escola a responsabilidade única pela reduzida preparação dos alunos, em Ciências e em qualquer outro domínio, também não é possível isentá-la de responsabilidades. Aliás, são muitos os países que procuram introduzir no sistema de ensino formal programas que contrariem a desmotivação dos alunos quanto à aprendizagem das Ciências e os aliciem pela escolha de carreiras profissionais afins. Uma das medidas a seguir é relevar o papel das Ciências nos primeiros anos para o desenvolvimento de atitudes e competências de valorização do conhecimento científico (Harlen, 2001).

Tal como defende Delval (2001), a Escola tem de se preocupar com as mudanças que ocorrem na sociedade $\mathrm{e}$ assumir como prioritário o desenvolvimento de competências dos indivíduos para detectar problemas, analisá-los criticamente, compreender o sentido das mensagens emitidas pelos meios de comunicação e estar atento às injustiças sociais geradas por desigualdades e problemas de dimensão planetária (GilPérez, Vilches, Astaburuaga e Edwards, 2000). A literacia científica é, porventura, uma das componentes da formação dos indivíduos capaz de dar um contributo positivo para esse fim. Mais ainda, se é certo que os meios tecnológicos tornam hoje possível o acesso instantâneo à informação, é também claro que informação não é o mesmo que conhecimento e que competências de descodificação e interpretação da informação serão, indubitavelmente, algo que a Escola deverá sempre promover. A educação, numa perspectiva cultural, deverá ter como propósito a compreensão da sociedade do seu tempo, com referência ao passado e com capacidade de prever implicações para o futuro. $\mathbf{0}$ conhecimento científico e tecnológico é parte integrante da cultura contemporânea e, por isso, será sempre uma ferramenta indispensável para o reforço do papel social, argumentativo e reivindicativo, das populações. Se é certo que se trata de um objectivo muito ambicioso não deveremos, apesar disso, ignorar que a literacia científica individual constitui a base para a definição do nível de compreensão pública da ciência que cada sociedade for capaz de evidenciar, este sim também um indicador crucial do desenvolvimento humano e sócioeconómico de cada país (Martins, 2004).

Existe um número cada vez maior de investigadores e educadores que advogam um ensino das ciências de orientação mais humanista entendido tal ensino como aquele que permite aos alunos compreender os fenómenos de cariz científico-tecnológico sejam eles do ambiente próximo ou mais remoto dos alunos, mas relativamente aos quais exista ou seja possível incentivar um interesse genuíno pela sua compreensão. Este tipo de educação em ciências que a escola deve ter como meta, implica alterações nas finalidades do processo 
educativo, nos papéis do aluno e do professor, e nos objectos de estudo e suas abordagens didáctico-pedagógicas (ver, por exemplo, Cachapuz, Praia e Jorge, 2002).

De forma resumida, e numa lógica de educação e não de simples instrução científica, a compreensão de conceitos deve ser enquadrada num leque vasto de competências, atitudes e valores que permitam aos alunos saber valorizar o papel do conhecimento numa perspectiva global de cidadania. A visão disciplinar representa uma via para aprofundamento de aspectos específicos em quadros de referência próprios, mas ao nível da ciência escolar a especialização disciplinar deve ser entendida como um contributo para uma visão interdisciplinar e transdisciplinar que a maioria dos problemas exige. Também a compreensão da história da ciência e de contextos sócio-culturais onde emergiu a produção de conhecimento científico ajudará à construção, por parte dos alunos, de uma visão mais humanista da ciência e dos cientistas.

Situando a presente discussão no âmbito da educação em ciências dos jovens, a nível básico e secundário, é merecedor de particular atenção o papel do professor e do aluno no processo de interacção didáctica. Destacamos dois pontos:

- o primeiro diz respeito ao papel que se atribui ao ensino formal das ciências. Embora seja cada vez mais frequente a referência à insatisfação da sociedade sobre as aprendizagens alcançadas em ambiente escolar, não é de todo plausível conceber uma aprendizagem das ciências inteiramente à margem da escola para sectores apreciáveis da população. Tal posicionamento resulta da natureza contra-intuitiva de muitos dos princípios científicos, o que exige, portanto, a organização de estratégias de ensino apropriadas muitas delas recorrendo a actividades prático-laboratoriais e experimentais que só professores preparados poderão conduzir e nas quais se utilizam equipamentos específicos, a maioria não acessíveis em ambientes não formais.
- o segundo ponto tem a ver com as finalidades da instituição escolar enquanto sistema organizado de ensino que deve promover, em cada um, um conjunto de saberes, competências e capacidades fundamentais ao seu crescimento pessoal, social e profissional. As ciências terão sempre de fazer parte do leque de saberes básicos numa sociedade onde o conhecimento científico e tecnológico é, indubitavelmente, aquilo que mais distingue a época actual das anteriores. A escola será, porventura, a via primordial para esbater as diferenças sociais que existem na maioria dos países, mesmo naqueles de maior desenvolvimento económico. A educação científica das populações, entendida não como a educação de cientistas mas como a educação em ciência de todos faz hoje parte do leque de preocupações dos responsáveis políticos, educadores e investigadores em todos os países desenvolvidos e em vias de desenvolvimento. Discutem-se e enunciam-se finalidades, objectivos e conteúdos curriculares e assume-se cada vez mais de forma explícita a necessidade de intervir para modificar os resultados que os estudos de avaliação internacional têm tornado públicos (por exemplo, o estudo PISA 2000).

Na segunda parte deste trabalho, a submeter ao próximo número do boletim "Química", far-se-á uma abordagem particular às relações da Literacia científica e da Literacia química com o Ensino da Química e aos princípios orientadores deste ensino,

particularmente no que concerne ao Ensino Secundário.

\section{Bibliografia}

Acevedo-Díaz, J. A. (2004). Reflexiones sobre las finalidades de la enseñanza de las ciencias: Educación científica para la ciudadanía. Revista Eureka sobre Enseñanza y Divulgación de las Ciencias, 1 (1), 3-16.

Acevedo-Díaz, J. A., Vázquez Alonso, A., Manassero Mas, M. A. (2003). Papel de la educación CTS en una alfabetización científica e tecnológica para todas las personas. Revista Electrónica de Enseñanza de las Ciencias, 2 (2). Versão electrónica $<$ http://www.saum.uvigo.es/reec/>
Cachapuz, A., Praia, J., Jorge, M. (2002). Ciência, Educação em Ciência e Ensino das Ciências. Lisboa: Ministério da Educação

Delval, J. (2001). Qué pretendemos en la educación? Investigación en la Escuela, 43 5-14.

Eurobarometer 55.2 (2001). Europeans, science and tecnhology. Versão electrónica $<$ http://pascal.iseg.utl.pt/ cisep/SeminarioPCC/forum.htm>

Gil-Pérez, D., Vilches, A., Astaburuaga, R., Edwards, M. (2000). La atención a la situación del mundo en la educación de los futuros ciudadanos y ciudadanas. Investigación en la Escuela, 40, 39-56.

Harlen, W. (2001). The Assessment of Scientific Literacy in the OECD/PISA Project. Em $\mathrm{H}$. Behrendt et al. (editors), Research in Science Education - Past, Present and Future, (pp. 49-60), Dordrecht, Boston, London: Kluwer Academic Publishers.

Kinstrey, R. (2004). Where, oh where, have the engineers gone? Solutions, 87 (10), pp. 36-38.

Martins, I. P. (2004). Literacia científica e contributos do ensino formal para a compreensão pública da ciência. Lição Síntese apresentada para Provas de Agregação em Educação (não publicado), Universidade de Aveiro (29-30 Janeiro 2004).

OECD (2000). Measuring student knowledge and skills: The PISA assessment of reading, mathematical and scientific literacy. Paris: OECD.

OECD (2003). The PISA 2003 Assessment Framework - Mathematics, Reading, Science and Problem Solving Knowledge and Skills. Paris: OECD.

Sen, A. (2003). Reflections on Literacy. Em N. Aksornkool (compiler), Literacy as Freedom. A UNESCO Round-table, (pp. 20-30), Paris: UNESCO, Literacy and Non-formal Education Section Division of Basic Education.

UNESCO, ICSU (1999). Ciência para o SécuIo XXI - Um novo Compromisso. Paris: UNESCO.

Walberg, H. J., Paik, S. (1997). Scientific Literacy as an International Concern. Em W. Graber, C. Bolte (editors), Scientific Literacy, (pp. 143-166), Kiel: IPN.

Wearmouth, J., Soler, J., Reid, G. (2003) Meeting Difficulties in Literacy Development. Research, policy and practice. London, New York: RoutledgeFalmer. 


\section{Inn livro teórico para as aulas práticas}

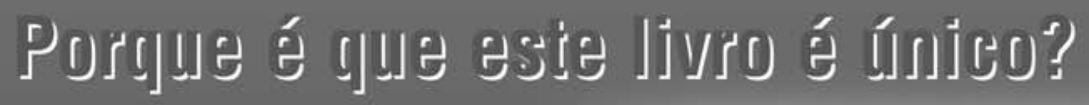

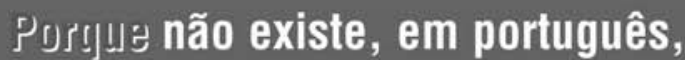
mais nenhuma obra que trate das regras gerais de "comportamento" num laboratório

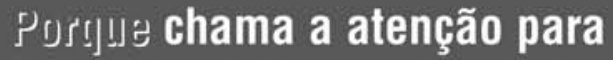
o problema da segurança nos laboratórios

Pอร!] de tópicos essenciais que, por falta de tempo, raramente são tratados nas aulas com um nível adequado:

- Elaboração de relatórios

- Pesquisa bibliográfica

- Aquisição automática de dados

- Análise e tratamento de dados experimentais

- Apresentação de dados em gráficos e medida de algumas propriedades

\section{GUIA DO LABORATÓRIO DE QUÍMICA E BIOQUÍMICA}

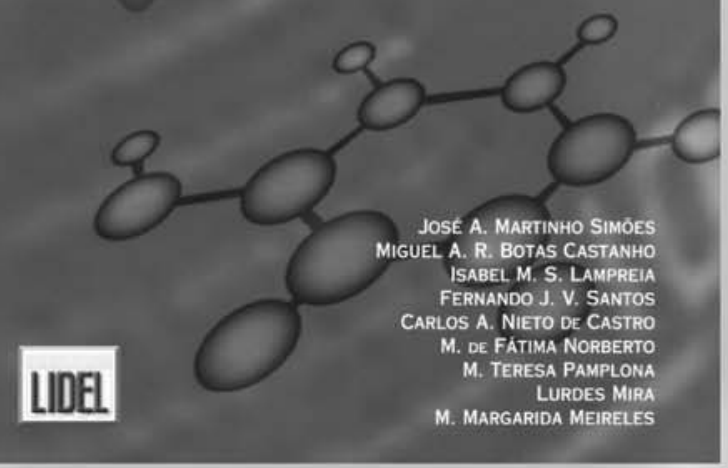

D: Direjios de Autor desia vida revertem a favor da

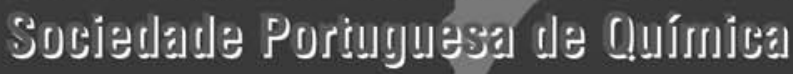

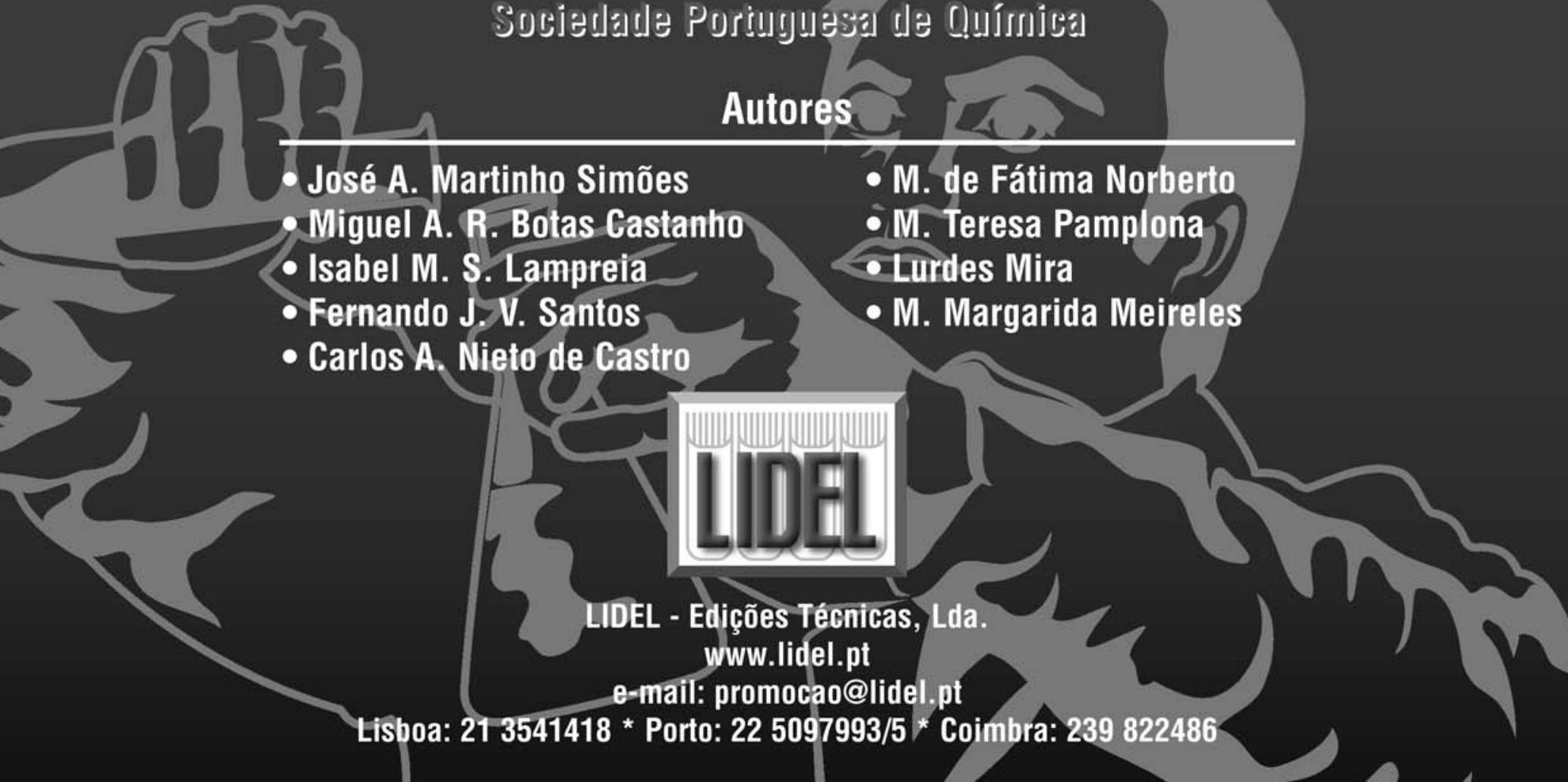

